\title{
ACESSIBILIDADE ESPACIAL DE DEFICIENTES FÍSICOS, VISUAIS E IDOSOS EM PARQUE PÚBLICO
}

\author{
SPATIAL ACCESSIBILITY FOR PEOPLE WITH PHYSICAL AND VISUAL DISABILITIES AND \\ OLDER PEOPLE IN PUBLIC GREEN SPACE
}

\author{
Dâmela Klein ${ }^{1}$

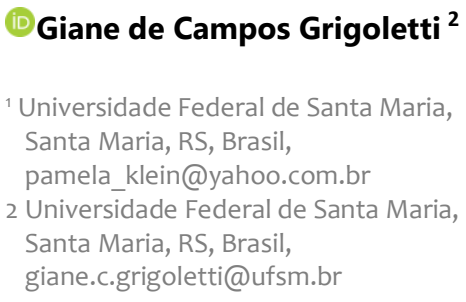

Contribuição dos autores:

PK: conceituação, curadoria de dados, análise formal, investigação, metodologia, validação, visualização, escrita - rascunho original, escrita - revisão e edição. GCG: conceituação, curadoria de dados, análise formal, metodologia, administração de projetos, supervisão, validação, visualização, escrita - rascunho original, escrita - revisão e edição.

Fomento: não houve fomento. Declaração de conflito: nada foi declarado.

Editor Responsável:

Sidney Piochi Bernardini (iD)

\begin{abstract}
Resumo
As circunstâncias em que se inserem pessoas com deficiência e mobilidade reduzida, além da perspectiva médica e individual, incluem uma perspectiva estrutural e social, em que $o$ ambiente tem um enorme impacto sobre a experiência e a extensão das suas dificuldades de mobilidade. Dentre as restrições enfrentadas, está o seu lazer, visto que é frequente, nas cidades brasileiras, encontrar espaços livres públicos de lazer que possuem falta de acessibilidade. Este artigo tem por objetivo apresentar uma avaliação de acessibilidade espacial, com foco em deficientes físicos, visuais e idosos, realizada no Parque João Goulart, em Santa Rosa, RS, por meio de vistoria técnica. O método baseou-se nas recomendações da NBR9050 e em componentes da acessibilidade espacial (deslocamento, orientação, uso e comunicação). Os resultados apontam que os espaços do parque não são totalmente acessíveis ao grupo estudado, apresentando problemas em relação a todos os componentes da acessibilidade espacial, a despeito do projeto ter buscado atender O PCD. O público menos atendido são os deficientes visuais e os mais atendidos, os idosos. Os resultados dessa pesquisa confirmam a contribuição das vistorias técnicas para melhor compreender e solucionar problemas relacionados à acessibilidade espacial e a importância de abordá-la a partir da compreensão das necessidades específicas de cada indivíduo em condição de mobilidade reduzida ou deficiência.
\end{abstract}

Palavras-chave: Parques públicos. Pessoas com mobilidade reduzida. Pessoas com deficiência. Idosos. Acessibilidade.

\begin{abstract}
The general background of people with disabilities, besides medical and individual perspectives, is associated with structural and social perspectives. The environment has a huge impact on their life experiences and the extent of their mobility difficulties. Among the restrictions faced, there is their recreation, since it is common, in Brazilian cities, to find public green spaces that have inadequate accessibility considering people with disabilities. This article aims to present an evaluation of spatial accessibility, focusing on people with physical and visual disabilities and older people, carried out at João Goulart Park, located in Santa Rosa, RS, through access audit. The method considered the recommendations of Brazilian standards and components of spatial accessibility (mobility, orientation, occupation and communication). The results show that the park spaces are not completely accessible to the studied groups; there are problems related to all components of spatial accessibility considered in this study, despite the intended application of Brazilian standards. People with visual disabilities are the ones who face the most difficulties. Older people face fewer difficulties. The results demonstrate that technical audits can contribute to understanding and solutions to problems related to spatial accessibility and the importance of thinking about accessibility from an understanding of the specific needs concerning disabilities or reduced mobility.
\end{abstract}

Keywords: Public green spaces. People with physical and visual disabilities. Older people. Accessibility.

How to cite this article:

KLEIN, P.; GRIGOLETTI, G. de C. Acessibilidade espacial de deficientes físicos, visuais e idosos em parque público. PARC Pesquisa em Arquitetura e Construção, Campinas, SP, v. 12, p. e021016, 2021. DOI: http://dx.doi.org/10.20396/parc.v12i00.8660648 


\section{Introdução}

Ambientes públicos, em geral, são projetados e construídos buscando atender pessoas com deficiência ou mobilidade reduzida. No entanto, observa-se que muitos espaços públicos ainda apresentam barreiras que dificultam a sua livre locomoção. Esse grupo enfrenta uma situação de exclusão, não usufruindo seu direito básico de igualdade de condições garantido pela Constituição Federal (BRASIL, 1988). As pessoas com deficiência ou mobilidade reduzida, ao depararem-se com barreiras físico-espaciais e atitudinais, tem sua participação na sociedade prejudicada em relação às pessoas sem restrições (BRASIL, 2015).

Entre os locais que podem ser inacessíveis a estes grupos estão os espaços livres públicos de lazer. O direito de acesso a esses locais pelos cidadãos está assegurado pela Constituição Federal, através do artigo $6^{\circ}$ : "são direitos sociais [...] o lazer, [...] na forma desta Constituição" (BRASIL, 1988). Outro importante ponto presente no documento é o direito de ir e vir previsto no inciso XV do artigo $5^{\circ}$ : "é livre a locomoção no território nacional [...].". No entanto, pessoas com deficiência ou mobilidade reduzida facilmente encontram barreiras físico-espaciais e atitudinais que as impedem de usufruírem esses direitos. Essa ideia representa o que a acessibilidade deve alcançar: oportunizar o uso comum, reconhecer e aceitar a diversidade, proporcionar a todos o livre acesso e reconhecer as especificidades daqueles que compõe a sociedade (ARANHA, 2000; MESHUR, 2013; SIU, 2013; WHO, 2016b). Conforme aponta Magnoli (2006, p. 182), além do sentido de igualdade entre as pessoas, o espaço livre público "[...] é o espaço da vida comunitária por excelência".

Considerando a importância desse atributo espacial, deve-se entender o conceito de espaços acessíveis e o de pessoa com deficiência (PCD) e mobilidade reduzida. Conforme a NBR 9050 (ABNT, 2020, p. 2), espaços acessíveis proporcionam condição de “[...] alcance, percepção e atendimento para utilização, com segurança e autonomia, de espaços, mobiliário, equipamentos urbanos, edificações, transportes, informação e comunicação [...]". Portanto, o conceito de acessibilidade está diretamente relacionado à quantidade e ao nível de barreiras existentes em determinado espaço (AGUIAR, 2010). Barreiras físico-espaciais propiciam situações que não apenas enfraquecem o conceito de espaço público, como também contribuem para uma sociedade segregada, hostil e intolerante. Ambientes inacessíveis estendem as limitações daquelas pessoas que possuem condições mais restritivas, sejam físicas ou mentais, ao passo que ambientes acessíveis contribuem para a usabilidade, a participação e a inclusão social (OMS, 2012; DORNELES; BINS ELY, 2013). Conforme a Lei Federal No 13.146, de 2015 (BRASIL, 2015), pessoa com deficiência é aquela que apresenta impedimento físico, mental, intelectual ou sensorial de longo prazo. A mesma lei considera pessoas com mobilidade reduzida aquelas que tenham dificuldade de movimentação, permanente ou temporária, gerando redução efetiva da mobilidade, da flexibilidade, da coordenação motora ou da percepção sensorial.

Segundo dados do Censo de 2010 (IBGE, 2020), 23,9\%, ou seja, 45,6 milhões de pessoas, apresentavam algum tipo de restrição ou deficiência. Desse total, 4,1\% possuíam deficiência mental ou intelectual, 20,8\% deficiência motora, 56,2\% deficiência visual e $15,3 \%$ deficiência auditiva. Quanto às pessoas com mobilidade reduzida, os idosos são o maior grupo e em crescimento. Além disso, o envelhecimento global possui forte tendência à deficiência, visto que, quanto maior a idade, maior o risco de a pessoa apresentar alguma limitação (OMS, 2005).

A deficiência física, que atinge 13 milhões de pessoas, no Brasil, é mais comum em homens e aumenta conforme o avanço da idade (IBGE, 2020). Mobiliário e pisos em 
condições inadequadas, como desníveis, tamanho e forma, podem prejudicar tanto o desenvolvimento de pessoas com deficiência física, pois elas passam longos períodos na posição sentada ou com postura inadequada, devido ao uso dos apoios, como causar cansaço mais rápido do que a uma pessoa com facilidade de locomoção e movimento (TAGLIARI; TRÊS; OLIVEIRA, 2006; SILVA et al., 2013).

De acordo com dados do IBGE (2020), o Brasil possui cerca de 36 milhões de pessoas com deficiência visual. Conforme a OMS (WHO, 2016a), a deficiência visual refere-se a faixa que vai da cegueira, classificada como grave, até a baixa visão, considerada moderada. Recorrente principalmente em idosos, a deficiência visual também abrange aqueles que apresentam apenas baixa visão, possível de ser corrigida através de procedimentos cirúrgicos. A visão é considerada um dos mais importantes sistemas que os humanos possuem a fim de auxiliar na comunicação com demais indivíduos e na orientação de forma segura e autônoma. Pessoas com deficiência visual necessitam aprimorar outros sentidos, tais como o tato, para perceber tipos de pisos e revestimentos, e a audição, para interpretar os sons do tráfego, de passos, de vozes, e o olfato, para captar os odores característicos de atividades humanas, como alimentos, queima do combustível e lixo, por exemplo (GIL, 2001; FROYEN, 2006, p.329 apud BRANDÃO, 2011, p. 27).

Dentre as perdas que a cegueira acarreta estão a mobilidade e a orientação, que abrange a execução de tarefas diárias, e os deslocamentos. Essa perda pode ser minimizada por meio de soluções que contemplam os demais sentidos do indivíduo, como sinalizações sonoras (audição) e em braile (tato), superfícies que podem ser percebidas através do tato, como os pisos podotáteis, e mesmo o contraste de cores, para mudança de nível ou orientação da superfície, em casos de visão subnormal (OMS, 2012; GIL, 2001).

Em relação aos idosos, ainda não há um consenso quanto à idade para ser assim considerado. Segundo o Estatuto do Idoso e o IBGE (2020), a idade é definida em 60 anos. Já a Constituição do Brasil (BRASIL, 1988) considera 65 anos. A OMS (2005) possui uma classificação baseada em condições socioeconômicas, considerando 65 anos em países desenvolvidos e 60 anos para os países em desenvolvimento, como é o caso do Brasil. No estudo apresentado neste artigo, considerou-se a idade de 60 anos, seguindo os critérios do Estatuto do Idoso, do IBGE (2020) e da OMS (2005).

Conforme dados estatísticos do IBGE (2020), em 2015, o número de idosos chegava a $14,3 \%$ da população brasileira. A perspectiva é que esse número cresça, chegando a superar o número de crianças de 0 a 14 anos, em 2030, e de jovens com até 29 anos em 2055. Segundo a OMS (2005), em 2025, o Brasil será o sexto país do mundo em número de idosos (IBGE, 2016; OMS, 2005; SOUZA, 2017).

Desde 2003, o Estatuto do Idoso estabelece que a população idosa apresenta necessidades como autonomia, mobilidade, acesso à informação, serviços, segurança e saúde preventiva, semelhantes às necessidades de deficientes físicos e visuais (BRASIL, 2003). Com o envelhecimento, há um declínio de habilidades funcionais e mentais, com a redução da visão, da audição, da capacidade de processamento de sinais vestibulares, visuais e proprioceptivos, que interfere no equilíbrio corporal, bem como com o aumento da obesidade. Este contexto, que não é linear em relação à idade e pode variar de indivíduo para indivíduo, irá interferir diretamente na autonomia e na mobilidade dos idosos (TERROSO et al., 2014; WHO, 2021; BUSHATSKY et al., 2019). Considerando a autonomia física e a mobilidade, um ambiente livre de obstáculos, de fácil manutenção, respeito às características e às limitações dos idosos, a fim de evitar acidentes e garantir a usabilidade do local de forma segura e confortável, é fundamental para garantir sua 
segurança. Quanto ao acesso à informação, este refere-se à facilidade de orientação e compreensão do contexto espacial e social, fundamental para os idosos na perspectiva de crescimento de suas limitações mentais. Além disso, os ambientes devem proporcionar controle da privacidade, interação social, senso de comunidade e de vizinhança (DORNELES, 2006; BUFFEL; PHILLIPSON; SCHARF, 2012).

Em relação à acessibilidade espacial, tema deste artigo, esta representa um atributo do ambiente que promove a fácil compreensão de sua função e organização, de quais atividades são ali realizadas e como se dá a relação desse com outros ambientes. Neste artigo, adota-se o termo acessibilidade espacial como um conjunto de estratégias, relacionadas ao acesso e interação do indivíduo com o local, que buscam eliminar as barreiras físico-espaciais existentes para que o uso possa ocorrer de forma autônoma, segura e confortável (DISCHINGER; BINS ELY; PIARDI, 2012; MESHUR, 2013).

Pode-se compreender a acessibilidade espacial por meio de quatro componentes: orientação, deslocamento, comunicação e uso (DISCHINGER; BINS ELY; PIARDI, 2012; MESHUR, 2013; DORNELES; BINS ELY, 2013). A orientação diz respeito à legibilidade proporcionada pela configuração ambiental e organizacional. Esse componente é fundamental para que o indivíduo possa se localizar, identificar o ambiente e definir qual o percurso que será tomado para chegar ao destino desejado a partir das informações fornecidas pelo próprio ambiente. A falta de orientação pode impedir o uso e até mesmo comprometer as condições básicas de saber onde se está, o que fazer e para onde ir. O deslocamento permite que as pessoas percorram o espaço em trajetos horizontais e verticais de maneira independente, segura e confortável. A comunicação refere-se à troca de informações interpessoais e da pessoa com o ambiente a fim de possibilitar o entendimento para a utilização de equipamentos e participação em atividades, podendo ter o auxílio da tecnologia. $O$ uso refere-se à facilidade de desenvolver atividades segundo as funções do espaço. Está diretamente relacionado a mobiliário e a equipamentos. Estes devem ser confortáveis e propiciar a participação de atividades e permitir as relações interpessoais.

Vários estudos têm sido encaminhados, tanto no Brasil, quanto no mundo, a fim de avaliar e contribuir com o desenvolvimento de espaços públicos de lazer mais acessíveis aos deficientes físicos, visuais e idosos. Dentre os métodos empregados, está a vistoria técnica, avaliação objetiva baseada em recomendações e exigências pré-estabelecidas em normas e legislações. A vistoria técnica é apontada como uma importante abordagem quando se deseja fazer uma avaliação objetiva ou comparar soluções implantadas. Embora ela não esgote a possibilidade de avaliação, pois a opinião dos usuários também é fundamental para a implementação de ações específicas para um determinado contexto social, econômico e cultural, ela tem sido usada na compreensão, avaliação e orientação de ações voltadas a melhoria de espaços públicos em diversos contextos (ITDP, 2016; FANTINI, 2014; DISCHINGER; BINS ELY; PIARDI, 2012; MONTENEGRO; SANTIAGO; SOUSA, 2009). Nos parágrafos seguintes, alguns estudos com abordagem objetiva baseados em vistoria técnica são apresentados.

Medeiros, Matias e Costa (2016) propuseram um trecho de rota acessível, para o centro Histórico de João Pessoa, Paraíba, de modo a tornar habitável dois lotes destinados à habitação de interesse social. Os registros ocorreram por meio de fotografias e levantamentos físicos segundo quatro formas: ilustração dos problemas encontrados através das fotografias; a descrição dos problemas, com base nas referências da NBR 9050, versão 2015, tendo como principal parâmetro a análise das larguras das calçadas; interpretação das referências, adequando-as para as situações encontradas; e por último, a proposta de uma solução. Segundo os autores, o estudo revelou a 
possibilidade de inserir a acessibilidade no local, visto que $99 \%$ das situações eram passíveis de adaptações ou superáveis com intervenções primárias.

Araújo, Cândido e Leite (2009) focaram no estudo da acessibilidade de pessoas com deficiência física, na cidade de Barra Mansa, Rio de Janeiro. A ferramenta usada baseouse em fichas avaliativas de acordo com a NBR 9050 (versão de 2004), aplicadas em diferentes locais públicos (parque, estação ferroviária e largo da igreja). A ficha continha observações descritivas e ilustrações a respeito de piso, da sinalização, escadas e rampas, sanitários e demais elementos. Os autores constataram que, embora houvesse a tentativa de garantir a acessibilidade no espaço estudado, este $\Theta$ espaçø não alcançava os padrões estabelecidos pelas normativas. Além disso, ressaltaram que o espaço não se torna acessível apenas com a presença de rampas de acessos ou vagas reservadas, mas sim, através de um local que transmita a sensação de segurança e independência.

Estudo encaminhado por Vasconcellos (2011), baseado nos componentes de acessibilidade espacial propostos por Dischinger, Bins Ely e Piardi (2009), já comentados anteriormente, buscou auxiliar na promoção de espaços acessíveis e equiparação de oportunidades de uso e vivência no ambiente construído através do desenho inclusivo. O método baseou-se em vistoria técnica através do preenchimento de planilhas que abrangem diversos parâmetros de acessibilidade avaliados conforme o atendimento para cada grupo de usuários e que pode ser aplicado em espaços abertos, como parques e ruas, como em edificações. A avaliação adotou um valor percentual dado através da identificação: 0 - restritivo; 1 - acessível. Através da aplicação, foi possível identificar quais aspectos e quais grupos de usuários são mais frequentemente afetados ou não. Com isso, foi possível indicar soluções direcionadas à reversão de quadros de inacessibilidade.

Magagnin, Fontes e Salcedo (2014), em Bauru, Yoshida, Alonge e Magagnin (2016), em Marília, SP, Magagnin e Molles (2016), no Centro Histórico de Poços e Caldas, MG, e Magagnin e Menezes (2016), em Santos, SP, desenvolveram estudos com foco na acessibilidade espacial de pedestres em geral, de deficientes físicos e visuais, pessoas com mobilidade reduzida e idosos. Os autores demonstraram que a vistoria técnica, baseada em indicadores de acessibilidade espacial, é um método eficaz para identificar problemas e propor soluções adequadas, conforme a necessidade de cada grupo. Em relação aos resultados, os autores apuraram que os elementos que mais comprometeram a acessibilidade foram a ausência de faixas de pedestres, pisos inadequados e com desníveis, interrupção de passeios, larguras de passeios insuficientes para locomoção confortável e segura e ausência de rampas, dentre outros.

No exterior, estudos também têm comprovado a inadequação de espaços públicos de lazer para PCD e pessoas com mobilidade reduzida. Estudo de Rimmer (2005) demonstrou que, para os EUA, a despeito da importância de atividades físicas regulares para pessoas com deficiência ou mobilidade reduzida, estas são as que menos têm acesso a espaços, sejam fechados ou abertos, que propiciem condições adequadas para essa prática. $O$ autor chama a atenção que os ambientes abertos, como espaços públicos de lazer, possuem condições de acessibilidade menores do que os fechados. Ele cita pistas de caminhada que impossibilitam um cadeirante e seu acompanhante de percorrê-las, devido a sua largura, e desníveis que não podem ser vencidos facilmente.

Baris e Uslu (2009) avaliaram a acessibilidade de PCD e pessoas com mobilidade reduzida em Ankara, na Turquia. Os autores apontam várias barreiras enfrentadas pelo grupo pesquisado, tais como meio-fio alto, desníveis desconfortáveis, pavimento irregular, posição de mobiliário nos passeios impedindo livre deslocamento, falta de locais e mobiliário para descanso, dentre outros. 
Siu (2013) estudou a acessibilidade em parques para deficientes visuais na cidade de Hong Kong. Seis parques foram incluídos na pesquisa, em diferentes localizações e escalas. A pesquisa envolveu consulta a agentes públicos, documentos legais e normas, e aos próprios deficientes físicos, para a análise dos ambientes. Os deficientes visuais tinham muitas limitações para desfrutarem dos espaços de forma independente. Por exemplo, a crença de que um mapa tátil apresentando os espaços é suficiente para dar segurança aos deficientes visuais. De acordo com a pesquisa, conforme o tamanho do parque, não é possível que os deficientes memorizem o mapa tátil de tal forma que possam percorrê-lo sem mais informações distribuídas ao longo dos caminhos. Também foi verificado a lógica dos pavimentos podotáteis que não estavam conectados, por exemplo, com placas em Braile de tal forma que, para chegar às informações, não havia guia no piso. Uma sugestão apresentada pelo autor foi o fornecimento de guias em braile para os deficientes visuais, desta forma, tornando-os mais independentes do sistema de informação próprio, cujo alto custo, muitas vezes, dificulta sua implantação.

Pesquisa de Güngör (2016), em Konya, Turquia, apontou que o PCD e pessoas com mobilidade reduzida também enfrentam várias barreiras, a despeito da aplicação de normas voltadas a eles. Dentre os problemas, que foram reconhecidos por meio de observação técnica, foram apontados largura inadequada de caminhos, vagas de estacionamentos que não priorizam o grupo alvo, pavimentação irregular, desníveis com inclinações de rampa inacessíveis ao cadeirante, objetos (como os frades) dispostos em pontos inadequados de caminhos, passeios e acessos ao parque, além de mobiliário não adaptado às necessidades do PCD.

Considerando o contexto exposto, o presente artigo apresenta os resultados da avaliação, por vistoria técnica, da acessibilidade espacial no Parque João Goulart, na cidade de Santa Rosa, interior do Rio Grande do Sul, considerando pessoas com deficiência física, visual e idosos. A partir da avaliação, discute-se as necessidades específicas desses grupos que não são atendidos e busca-se contribuir com recomendações adicionais a NBR9050, aplicáveis a diversos contextos. Este estudo soma-se a outro efetuado no mesmo local, porém com foco na opinião de deficientes físicos, visuais e idosos, ainda não publicado.

\section{Método}

O método de avaliação, baseado em vistoria técnica, apoiou-se nos estudos de Vasconcellos (2011) e Dischinger, Bins Ely e Piardi (2009), conforme procedimentos descritos a seguir. A partir dos resultados, buscou-se traçar diretrizes que complementem aquelas já recomendadas na NBR 9050 (ABNT, 2020).

\section{Apresentação do Parque João Goulart}

O Parque João Goulart, situado na cidade de Santa Rosa, RS, iniciou-se como uma praça, ainda na década de 1940, em área junto à antiga estação férrea da cidade de Santa Rosa. A partir de 2000, com a desativação total da linha, o local sofreu uma expansão e passou a ocupar uma área de aproximadamente 4,8 ha. O parque, ao longo de sua existência, passou por inúmeras reformas e adequações. Atualmente, configura-se como um local aberto, sem muros ou grades, permitindo o livre acesso de pessoas em todo seu perímetro. Sua trama de caminhos define áreas que se assemelham a quadras e existem vagas de estacionamento na área interna, bem como nas vias adjacentes, para carros, ônibus, motos e ambulâncias.

O local abriga vários equipamentos públicos, como um posto da brigada militar, um museu municipal, lojas comerciais e o mercado público do município. Possui vários atrativos para lazer, como playgrounds, quadras esportivas, pista de skate, além de 
KLEIN, P.; GRIGOletTI, G. de C.

Acessibilidade espacial de deficientes físicos, visuais e idosos em parque público

gramados tanto sombreados quanto ensolarados. No parque, acontecem os principais eventos públicos culturais da cidade, sendo frequentado por um público bastante heterogêneo (SANTA ROSA, 2004).

Para a análise e avaliação, o parque, com $48.016 \mathrm{~m}^{2}$, foi subdividido em 7 áreas, denominadas quadras de referência, conforme mostrado na Figura 1. A demarcação dos limites das áreas foi dada através da rede de caminhos e dos equipamentos públicos. Tem-se, na quadra 01, um posto da brigada militar e um centro comercial, nas quadras 02 e 03, playgrounds, na quadra 04, as águas dançantes, na quadra 05, quadras esportivas, na quadra 06, o mercado público e, na quadra 07, o Museu Municipal, sanitários e pista de skate.

Figura 1 - Imagem aérea do Parque João Goulart e das sete quadras de referência

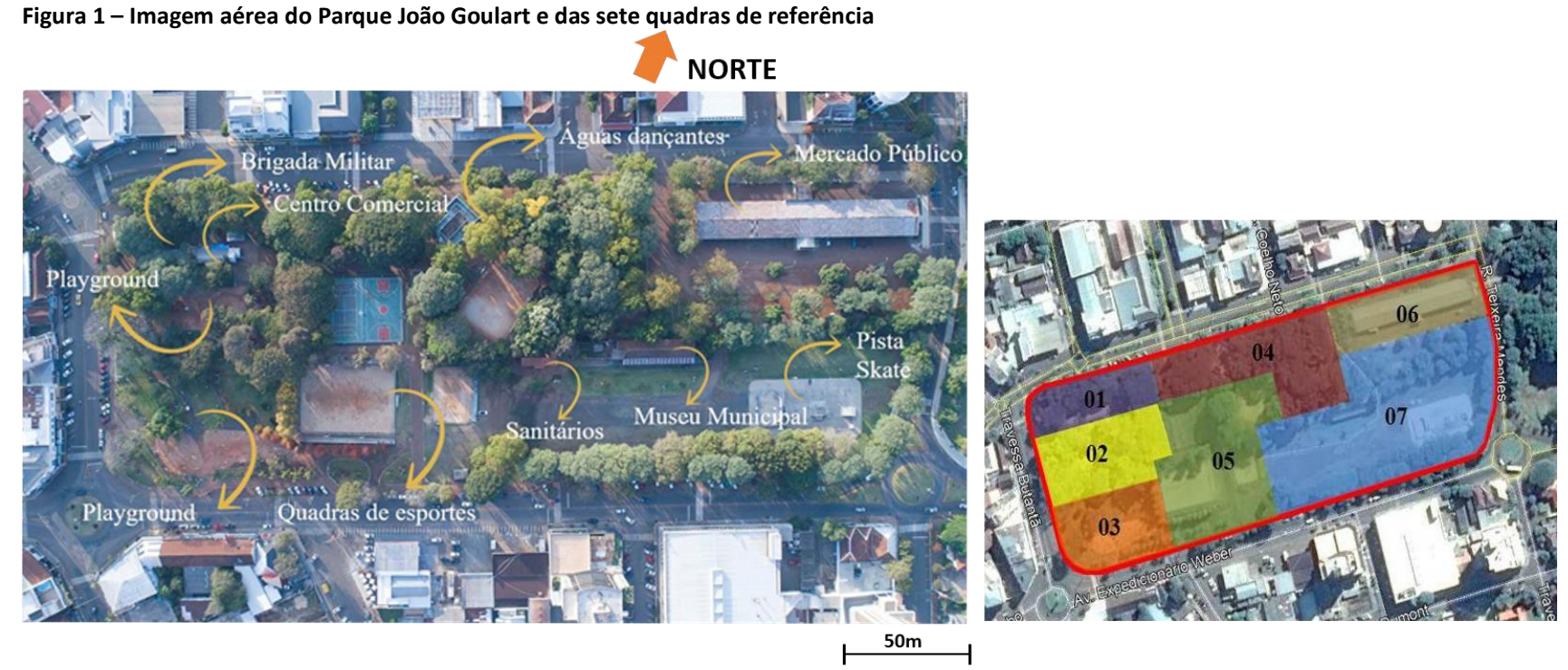

Fonte: adaptado de Google Earth (2014)

\section{Procedimentos e ferramenta de obtenção de dados}

Os critérios de avaliação basearam-se em Dischinger, Bins Ely e Piardi (2009) e Vasconcellos (2011), considerando os quatro componentes propostos pelos autores citados: orientação, deslocamento, comunicação e uso. Os procedimentos aplicados envolveram vistorias técnicas registradas em planilhas desenvolvidas por Dischinger, Bins Ely e Piardi (2009) e adaptadas por Vasconcellos (2011). As planilhas foram atualizadas e ajustadas para adequar-se a NBR9050 (ABNT, 2020) e acrescidas de itens julgados importantes para a análise do parque, ou seja, mobiliário urbano, sanitários e iluminação pública, referenciados pela NBR 5101 (ABNT, 2012).

As planilhas, como ferramentas de avaliação quantitativa, consideraram as necessidades dos três grupos mais expressivos de pessoas com deficiência e mobilidade reduzida na cidade de Santa Rosa (deficientes físicos, visuais e idosos) (IBGE, 2020), facilitando a análise e a identificação de possíveis ações para melhorias na sua acessibilidade espacial. A leitura de cada quesito, que se conforma como uma pergunta, foi feita considerando cada tipo usuário. Buscou-se determinar se o público específico foi atendido pelo espaço, de forma autônoma e segura ou se o espaço não lhe deu condições de acessibilidade.

A Figura 2 apresenta o cabeçalho da planilha adaptada de Vasconcellos (2011, p. 166), onde é possível visualizar sua organização. A planilha completa possui 98 quesitos de acessibilidade avaliados. A planilha divide-se em seis grandes grupos: circulação externa (59 quesitos), acesso de veículos e vagas de estacionamento (2 quesitos), faixa de 
KLEIN, P.; GRIGOletTI, G. de C.

Acessibilidade espacial de deficientes físicos, visuais e idosos em parque público

travessia de pedestres (7 quesitos), sanitários (21 quesitos), iluminação (3 quesitos) e sinalização (6 quesitos). Os quesitos referem-se ao tema de acessibilidade do grupo ao qual pertencem. Esses quesitos possuem indicação do componente espacial de acessibilidade relacionado a ele (deslocamento, uso, orientação e comunicação, indicados na terceira coluna da tabela, sob o título 'classe'). Dada a sua extensão, apresentou-se apenas o cabeçalho para entendimento.

Figura 2 - Recorte da planilha técnica usada como referência onde os grifos em vermelho indicam os componentes de acessibilidade de cada quesito e os grandes grupos

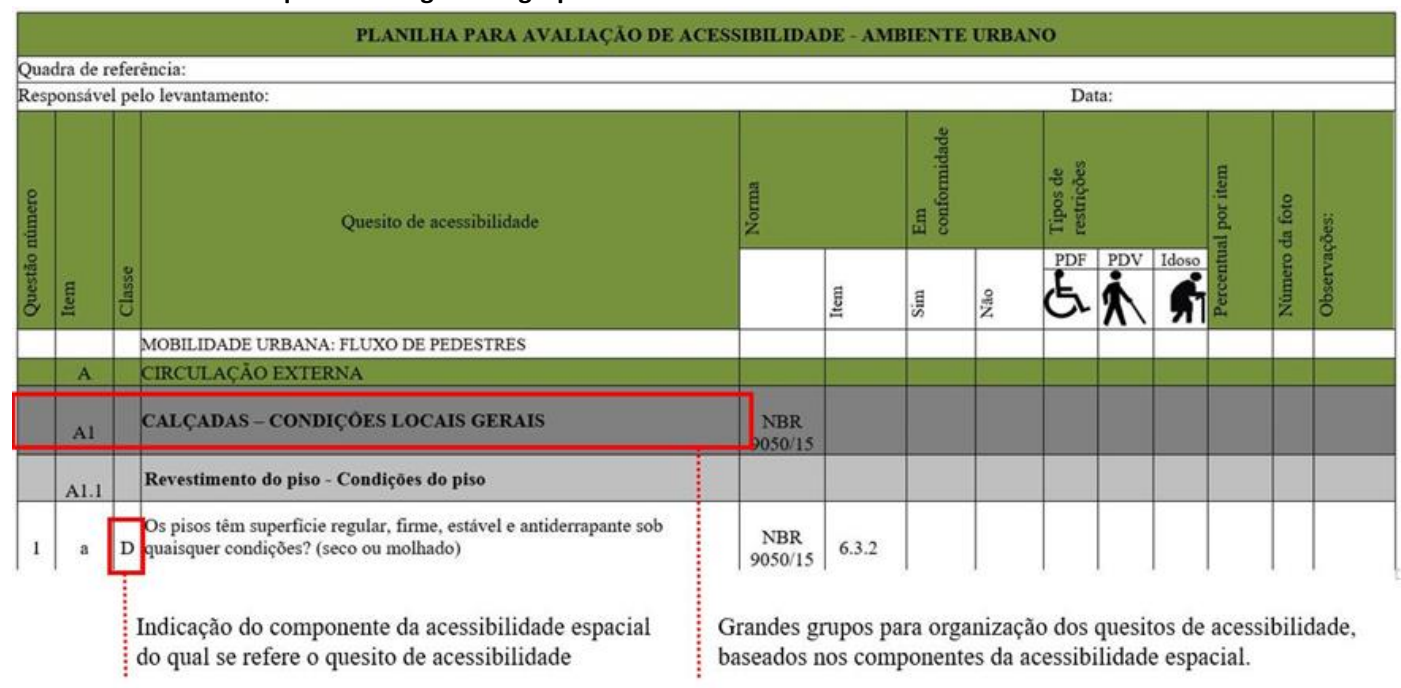

Fonte: adaptado de Vasconcellos (2011).

A Tabela 1 ilustra de forma esquemática a organização geral da planilha e seus principais temas.

Tabela 1 - Organização esquemática da planilha com a apresentação dos principais temas abordados, com o quantitativo dos quesitos analisados para cada público

\begin{tabular}{|c|c|c|c|}
\hline Grupos & Subgrupos & Subgrupos & $\begin{array}{c}\text { Números de } \\
\text { quesitos }\end{array}$ \\
\hline \multirow{9}{*}{$\begin{array}{l}\text { A - Circulação } \\
\text { Externa }\end{array}$} & \multirow{4}{*}{ A1 - Calçadas - condições locais gerais } & A1.1 Revestimento de piso & 3 \\
\hline & & A1.2 Aplicação do piso tátil & 7 \\
\hline & & A1.3 Mobiliário e equipamentos urbanos & 17 \\
\hline & & A1.4 Características das calçadas & 6 \\
\hline & A2 - Inclinação & & 3 \\
\hline & \multirow{3}{*}{ A3 - Desníveis } & A3.1 Condições gerais de nivelamento do piso & 5 \\
\hline & & $\begin{array}{l}\text { A3.2 Existência de coletores, caixas de inspeção, grelhas } \\
\text { e juntas de dilatação }\end{array}$ & 3 \\
\hline & & A3.3 Rebaixamento de calçada em pontos de travessia & 9 \\
\hline & A4 - Vegetação sobre a calçada & & 6 \\
\hline $\begin{array}{l}\text { B - Acesso de } \\
\text { veículos e vagas de } \\
\text { estacionamento }\end{array}$ & & & 2 \\
\hline \multirow{2}{*}{$\begin{array}{c}\text { C- Faixas de } \\
\text { travessias de } \\
\text { pedestres }\end{array}$} & C1 - Faixa de travessia & & 1 \\
\hline & C2 - Sinalização das faixas de travessia & & 6 \\
\hline D - Sanitários & & & 22 \\
\hline E - Iluminação & & & 3 \\
\hline F - Sinalização & & & 6 \\
\hline
\end{tabular}

Fonte: as autoras.

As vistorias técnicas, com o registro na planilha, ocorreram entre setembro de 2018 e setembro de 2019. Os registros feitos, durante as vistorias, foram complementados com registros fotográficos, a fim de ilustrar o local, e através de medições também registradas. A planilha foi aplicada para cada quadra de referência, ou seja, o parque 
KLEIN, P.; GRIGOletTI, G. de C.

Acessibilidade espacial de deficientes físicos, visuais e idosos em parque público

resultou em 7 planilhas de dados. Cada quesito de acessibilidade foi analisado de forma individual para cada público estudado (pessoas com deficiência física, visual e idosos).

\section{A análise dos dados}

O preenchimento da planilha admitiu dois valores, o (zero), quando o atendimento do usuário foi significativamente comprometido devido a não conformidade do espaço, e 1 (um), quando o usuário tem o atendimento garantido pela conformidade do espaço.

Quando o quesito de acessibilidade se direciona principalmente para um público, como por exemplo, o número 04 - Existe sinalização tátil (direcional e alerta) nos pisos das calçadas? - que se destina especialmente às pessoas com deficiência visual, considerouse para as pessoas com deficiência física e os idosos que a existência de piso tátil não influencia negativamente na sua acessibilidade, logo foi indicado como em conformidade, ou seja, com o valor 1 .

Após a análise, feita para todos os públicos, determinou-se um resultado final percentual, dado através de média aritmética simples, para cada um dos 98 quesitos, ilustrado na Figura 3.

Figura 3 - Recorte da planilha onde os grifos em vermelho indicam como visualizar os resultados das condições e percentuais

Resultado em percentual da condição geral de acessibilidade de cada usuários

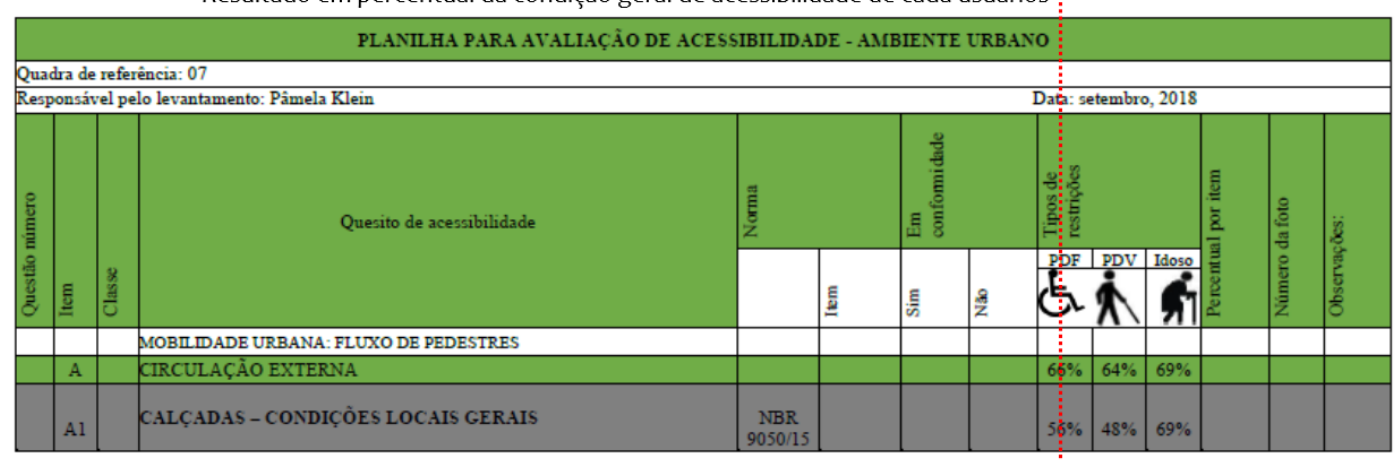

\begin{tabular}{|c|c|c|c|c|c|c|c|c|c|c|c|c|}
\hline & A3.3 & & $\begin{array}{l}\text { Rebaixamento de calçadas em pontos destinados à traressia de via } \\
\text { pública }\end{array}$ & & & & & $75 \%$ & $75 \%$ & $75 \%$ & & \\
\hline 45 & a & D & $\begin{array}{l}\text { Nas calçadas, em locais com faixa destinada à travessia de pedestres em via } \\
\text { pública, há rebaixamento do meio-fio e rampa sobre a calçada ou a calçada } \\
\text { presenta-se rebaixada? }\end{array}$ & & & Sim & & 1 & 1 & 1 & $100 \%$ & \\
\hline 46 & $\mathrm{~b}$ & D & $\begin{array}{l}\text { Há uma faixa de circulação plana, livre e continua na calçada em frente à } \\
\text { ampa? }\end{array}$ & $\begin{array}{c}\text { NBR } \\
9050 / 15 \\
\end{array}$ & 6.12 .7 .3 & Sim & & 1 & 1 & 1 & $100 \%$ & \\
\hline 47 & c & D & $\begin{array}{l}\text { A faixa de circulação da calçada em frente à rampa tem, no mínimo, } 120 \mathrm{~cm} \\
\text { le largura? }\end{array}$ & \begin{tabular}{c|c|} 
NBR \\
$9050 / 15$ \\
\end{tabular} & 6.12 .7 .3 & Sim & & 1 & 1 & 1 & $10,9 \%$ & \\
\hline 48 & d & D & A rampa possui largura mínima de $1,50 \mathrm{~m}$ ? & \begin{tabular}{|c|} 
NBR \\
$9050 / 15$ \\
\end{tabular} & 6.12 .7 .3 & Sim & & 1 & 1 & 1 & $10,0 \%$ & \\
\hline 49 & e & D & A inclinação da rampa e abas laterais é constante e não superior a $8,33 \%$ ? & $\begin{array}{c}\text { NBR } \\
9050 / 15 \\
\end{array}$ & 6.12 .7 .3 & & Não & 0 & 0 & 0 & $0 \%$ & \\
\hline 50 & $\mathrm{f}$ & D & $\begin{array}{l}\text { Há bordas laterais na rampa evitando degraus entre os pisos da rampa e a } \\
\text { alçada? }\end{array}$ & & & Sim & & 1 & 1 & 1 & $100 \%$ & \\
\hline 51 & $\mathbf{g}$ & D & $\begin{array}{l}\text { Há continuidade entre piso da rampa e da via pública, sem interrup̧̧ão por } \\
\text { legraus? }\end{array}$ & $\begin{array}{c}\text { NBR } \\
9050 / 15 \\
\end{array}$ & 6.12.7.3.1 & Sim & & 1 & : & 1 & 10p\% & \\
\hline 52 & h & D & piso da rampa é revestido com material antiderrapante? & \begin{tabular}{c|c|} 
NBR \\
$9050 / 15$ \\
\end{tabular} & 6.2 .3 & Sim & & 1 & 1 & 1 & $10 \underline{0} \%$ & \\
\hline 53 & i & D & $\begin{array}{l}\text { Am calçadas estreitas, há redução do percurso da travessia, faixa elevada } \\
\text { para travessia ou rebaixamento total da largura da calçada, com largura } \\
\text { línima de } 1,50 \text { m e com rampas laterais com inclinação máxima de } 5 \% \text { ? }\end{array}$ & $\begin{array}{c}\text { NBR } \\
9050 / 15\end{array}$ & 6.12.7.3.4 & & & & & & & $\begin{array}{r}\text { Não se } \\
\text { aplica }\end{array}$ \\
\hline
\end{tabular}

Fonte: Adaptado de Vasconcellos (2011).

Uma vez calculadas os percentuais, as avaliações foram feitas a partir dos valores alcançados por cada quesito e por público. Por exemplo, qual o atendimento de acessibilidade para cada público, qual quadra de referência proporcionou melhores condições de acessibilidade de forma geral e para cada público, qual o nível de 
acessibilidade do parque como um todo, quais temáticas são mais acessíveis, por quadra e para o parque como um todo.

Em relação à análise dos componentes de acessibilidade, os dados foram organizados segundo a descrição da coluna 'classe', terceira coluna à esquerda, na Figura 3, destacado em vermelho), em que os componentes são indicados pela sua letra inicial ( $C$ - comunicação, D - deslocamento, O - orientação, U - uso). Desta forma é possível verificar, quantitativamente, quais quesitos relacionados aos componentes foram mais ou menos atendidos.

\section{Resultados e discussão}

A Tabela 2 apresenta as percentagens atingidas pelas quadras individualmente, a partir da vistoria técnica para os quesitos de acessibilidade espacial considerados na pesquisa.

A Quadra 1 é caracterizada como área de passagem (predominância de circulações). $O$ grupo menos favorecido, nesta quadra, é o deficiente visual, principalmente no que diz respeito à sinalização. Não se verifica a presença de sinais ou informações em braile ou sinais sonoros, vital para esse público. Além disso, a travessia de pedestres e a circulação também são comprometidos pela falta de pisos podotáteis.

A Quadra 2 é composta por brinquedos metálicos e cobertura de areia, em boa parte da área. É bastante frequentada por idosos acompanhando crianças. A análise resultou em percentagens praticamente iguais para os três grupos, com o quesito de menor percentagem relacionado à circulação, uma vez que o piso de areia é inadequado para quem usa cadeira de rodas ou bengala.

A Quadra 3 é composta por um playground, com brinquedos em madeira. O piso predominante é em areia e pedra britada, também dificultando a circulação. No entanto, para as pessoas com deficiência visual, além da dificuldade de circulação, há ausência de sinalização adequada a eles. Não há estacionamentos diretamente ligados ao local, o que impede o embarque e desembarque de passageiros com mobilidade comprometida junto ao espaço.

A Quadra 4 possui uma edificação com piscina de águas dançantes. O grupo menos favorecido também é o de deficientes visuais, no que tange a travessia de pedestres. Nesta quadra verifica-se que as faixas de segurança não possuem continuidade no passeio, conforme pode ser visto na Figura 4. Também não há presença de sinais sonoros e pisos podotáteis.

A Quadra 5 é caracterizada pelas atividades desportivas, porém, não há nenhum mobiliário específico voltado ao público da pesquisa. Novamente, os deficientes visuais são os mais desfavorecidos pela inexistência de sinalização apropriada.

A Quadra 6, que abriga o mercado público municipal, com feiras acontecendo três vezes por semana, é local bastante frequentado pela população. Nessa área, há um desnível de $75 \mathrm{~cm}$ que marca o limite entre o passeio e a área aberta da feira, sem guarda-corpo. Para vencê-lo, é necessário contornar a área (Figura 5). Em decorrência da falta de sinalização em alguns pontos, os deficientes visuais são bastante desfavorecidos neste quesito, inclusive comprometendo sua segurança, devido ao desnível existente.

A Quadra 7 abriga um museu e os únicos sanitários do parque. O acesso aos sanitários não possui nenhum sistema que facilite a orientação e a autonomia do público alvo, como piso podotátil. Nas áreas abertas, rampas e circulações estão adequadas às necessidades dos usuários que são o foco deste estudo. As travessias de pedestres que dão acesso a essa área, no entanto, estão mal dimensionadas e sinalizadas. 
KLEIN, P.; GRIGOletTI, G. de C.

Acessibilidade espacial de deficientes físicos, visuais e idosos em parque público

Tabela 2 - Resultados da observação técnica para cada uma das sete quadras que compõem o Parque João Goulart.

\begin{tabular}{|c|c|c|c|}
\hline Quesitos & Pessoas com deficiência física & Pessoas com deficiência visual & Idosos \\
\hline \multicolumn{4}{|c|}{ Quadra 1 - abriga um centro comercial e posto da Brigada Militar } \\
\hline Circulação & $65 \%$ & $61 \%$ & $67 \%$ \\
\hline Estacionamento & $100 \%$ & $100 \%$ & $100 \%$ \\
\hline Travessia de Pedestres & $80 \%$ & $60 \%$ & $80 \%$ \\
\hline Sanitários & Não se aplica & Não se aplica & Não se aplica \\
\hline Iluminação & $33 \%$ & $33 \%$ & $33 \%$ \\
\hline Sinalização & $83 \%$ & $17 \%$ & $83 \%$ \\
\hline Média final & $72 \%$ & $54 \%$ & $73 \%$ \\
\hline \multicolumn{4}{|c|}{ Quadra 2-abriga o playground mais antigo do parque } \\
\hline Circulação & $46 \%$ & $45 \%$ & $53 \%$ \\
\hline Acesso de veículos e vagas de estacionamento & $100 \%$ & $100 \%$ & $100 \%$ \\
\hline Travessia de Pedestres & Não se aplica & Não se aplica & Não se aplica \\
\hline Sanitários & Não se aplica & Não se aplica & Não se aplica \\
\hline Iluminação & $67 \%$ & $67 \%$ & $67 \%$ \\
\hline Sinalização & $0 \%$ & $0 \%$ & $0 \%$ \\
\hline Média final & $53 \%$ & $53 \%$ & $55 \%$ \\
\hline \multicolumn{4}{|c|}{ Quadra 3-abriga o playground mais novo do parque } \\
\hline Circulação & $64 \%$ & $59 \%$ & $69 \%$ \\
\hline Estacionamento & $0 \%$ & $0 \%$ & $0 \%$ \\
\hline Travessia de Pedestres & $80 \%$ & $60 \%$ & $80 \%$ \\
\hline Sanitários & Não se aplica & Não se aplica & Não se aplica \\
\hline Iluminação & $33 \%$ & $33 \%$ & $33 \%$ \\
\hline Sinalização & $83 \%$ & $17 \%$ & $83 \%$ \\
\hline Média final & $52 \%$ & $34 \%$ & $53 \%$ \\
\hline \multicolumn{4}{|c|}{ Quadra 4-com jardim com águas dançantes } \\
\hline Circulação & $63 \%$ & $61 \%$ & $66 \%$ \\
\hline Acesso de veículos e vagas de estacionamento & $50 \%$ & $50 \%$ & $50 \%$ \\
\hline Travessia de Pedestres & $30 \%$ & $10 \%$ & $30 \%$ \\
\hline Sanitários & Não se aplica & Não se aplica & Não se aplica \\
\hline Iluminação & $67 \%$ & $67 \%$ & $67 \%$ \\
\hline Sinalização & $83 \%$ & $17 \%$ & $83 \%$ \\
\hline Média final & $58 \%$ & $41 \%$ & $59 \%$ \\
\hline \multicolumn{4}{|c|}{ Quadra 5-com quadras de esportes } \\
\hline Circulação & $67 \%$ & $64 \%$ & $69 \%$ \\
\hline Acesso de veículos e vagas de estacionamento & $0 \%$ & $0 \%$ & $0 \%$ \\
\hline Travessia de Pedestres & Não se aplica & Não se aplica & Não se aplica \\
\hline Sanitários & Não se aplica & Não se aplica & Não se aplica \\
\hline Iluminação & $67 \%$ & $67 \%$ & $67 \%$ \\
\hline Sinalização & $83 \%$ & $17 \%$ & $83 \%$ \\
\hline Média final & $54 \%$ & $37 \%$ & $55 \%$ \\
\hline \multicolumn{4}{|c|}{ Quadra 6-abriga o mercado público } \\
\hline Circulação & $66 \%$ & $64 \%$ & $68 \%$ \\
\hline Acesso de veículos e vagas de estacionamento & $50 \%$ & $50 \%$ & $50 \%$ \\
\hline Travessia de Pedestres & $30 \%$ & $10 \%$ & $30 \%$ \\
\hline Sanitários & Não se aplica & Não se aplica & Não se aplica \\
\hline Iluminação & $67 \%$ & $67 \%$ & $67 \%$ \\
\hline Sinalização & $83 \%$ & $17 \%$ & $83 \%$ \\
\hline Média final & $59 \%$ & $42 \%$ & $60 \%$ \\
\hline \multicolumn{4}{|c|}{ Quadra 7-abriga um museu municipal e sanitários } \\
\hline Circulação & $66 \%$ & $64 \%$ & $69 \%$ \\
\hline Acesso de veículos e vagas de estacionamento & $0 \%$ & $0 \%$ & $0 \%$ \\
\hline Travessia de Pedestres & $80 \%$ & $60 \%$ & $80 \%$ \\
\hline Sanitários & $25 \%$ & $25 \%$ & $30 \%$ \\
\hline Iluminação & $67 \%$ & $67 \%$ & $67 \%$ \\
\hline Sinalização & $83 \%$ & $17 \%$ & $83 \%$ \\
\hline Média final & $53 \%$ & $39 \%$ & $55 \%$ \\
\hline
\end{tabular}

Fonte: as autoras. 
KLEIN, P.; GRIGOletTI, G. de C.

Acessibilidade espacial de deficientes físicos, visuais e idosos em parque público

Figura 4 - Quadra 4 e condições das travessias de pedestres, embora haja a faixa de segurança, suas cabeceiras são interrompidas e não há sinais sonoros ou táteis para deficientes visuais
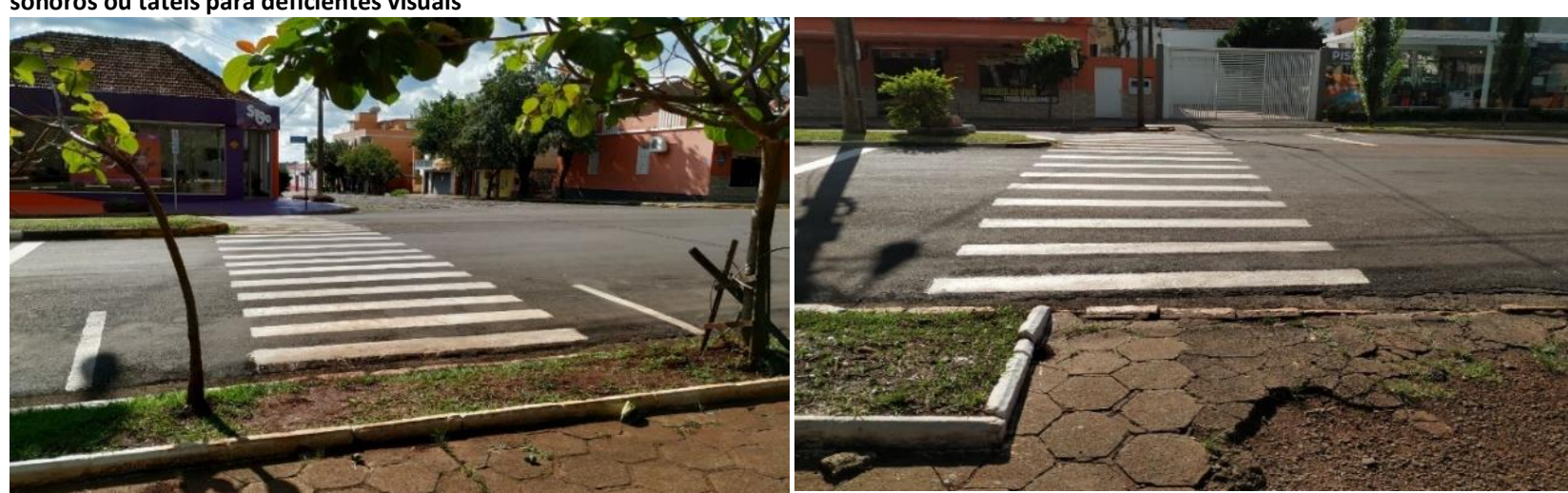

Fonte: as autoras.
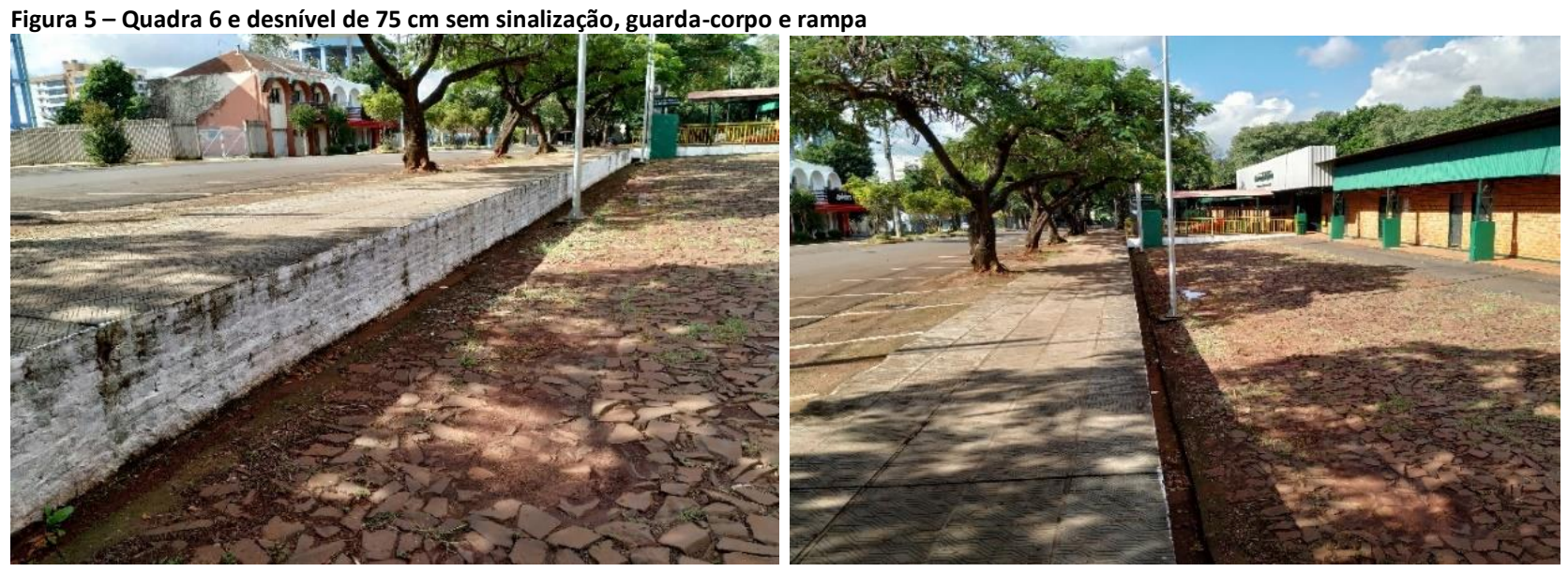

Fonte: as autoras.

De modo geral, para todas as quadras, há iluminação intermediária, ou seja, com postes destinados a circulação de pedestres. A iluminação superior, com postes de maior altura a fim de proporcionar uma iluminação geral, está localizado apenas em alguns pontos, o que pode gerar locais bastante escuros, especialmente onde não há redes de caminhos para pedestres.

Também há só um conjunto de sanitários, o que faz com que as pessoas tenham que se deslocar além dos $50 \mathrm{~m}$ recomendados pela NBR 9050. Ainda, os sanitários não possuem guias no piso, mapa ou informações em braile que auxiliem os deficientes visuais na identificação do mobiliário. Não há sanitário familiar ou exclusivo para deficientes, com entradas independentes.

De modo geral, para todo o parque, os pavimentos são precários, com desníveis pontuais, irregulares, sem piso podotátil, o que dificulta a locomoção com segurança dos três grupos estudados. No entanto, as larguras dos passeios estão, em sua maioria, de acordo com as recomendações da norma.

Os estacionamentos, embora presentes em quase todo o perímetro do parque e em seu interior, não atendem plenamente o público alvo, pois, nem todos possuem vagas exclusivas para eles e nem rampas que vençam desníveis presentes.

Nota-se que, devido ao uso de pavimentos maleáveis, a acessibilidade de alguns espaços fica comprometida para pessoas com bengala e cadeirantes, como o playground e as quadras desportivas. 
KLEIN, P.; GRIGOletTI, G. de C.

Acessibilidade espacial de deficientes físicos, visuais e idosos em parque público

O grupo dos deficientes visuais são os menos atendidos pela estrutura do parque. Já os idosos, de acordo com a análise, é o grupo mais favorecido. A Tabela 3 apresenta as percentagens atingidas pelo parque como um todo, de acordo com as médias obtidas a partir dos resultados de cada Quadra, segundo os grupos pesquisados.

Tabela 3 - Resultados da observação técnica para o Parque João Goulart como um todo

\begin{tabular}{|c|c|c|c|c|}
\hline & Pessoas com deficiência física & Pessoas com deficiência visual & Idosos & Média final \\
\hline Circulação & $62 \%$ & $60 \%$ & $66 \%$ & $62 \%$ \\
\hline Estacionamento & $43 \%$ & $43 \%$ & $43 \%$ & $43 \%$ \\
\hline Travessia de Pedestres & $60 \%$ & $40 \%$ & $60 \%$ & $53 \%$ \\
\hline Sanitários & $25 \%$ & $25 \%$ & $30 \%$ & $27 \%$ \\
\hline Iluminação & $57 \%$ & $57 \%$ & $57 \%$ & $57 \%$ \\
\hline Sinalização & $71 \%$ & $15 \%$ & $71 \%$ & $52 \%$ \\
\hline Todos os elementos & $52 \%$ & $40 \%$ & $55 \%$ & $49 \%$ \\
\hline
\end{tabular}

Fonte: as autoras.

O percentual mais baixo refere-se aos sanitários (27\%), seguidos pelos estacionamentos (43\%). Os melhores quesitos foram a circulação, devido as larguras e devido à própria topografia, que exige poucas rampas. Logo após, a iluminação que, embora contemple a área de visibilidade de um pedestre, não está presente em todo o local.

A estrutura atual do parque, apesar dos problemas apontados, pode facilmente ser adequada às necessidades de deficientes físicos, visuais e idosos. Ao longo do tempo, o parque tem passado por reformas e manutenção. No entanto, nota-se que as ações visando a acessibilidade espacial são pontuais (como o piso podotátil que não se estende a todos os ambientes do parque), desconectadas (como as faixas de travessia de pedestres que não se relacionam com o passeio), e, devido a isso, muitas vezes ineficientes. Haveria necessidade de um planejamento que incluísse um projeto integral e coerente que pudesse ser implantado, mesmo que a médio e longo prazos e em partes, em todo o parque.

A relação dos componentes de acessibilidade com os públicos estudados pode ser observada na Tabela 4. Quanto ao deslocamento (pisos adequados, caminhos sem obstáculos, guias de canteiros e passeios, larguras adequadas, rampas, inclinações, corrimãos, continuidade dos caminhos, etc.), o público menos atendido são as pessoas com deficiência física. Esse resultado é reflexo das condições de piso, que, em muitos pontos, encontra-se irregular, com saliências, com desníveis, sem piso podotátil, e com mobiliário ou árvores que se configuram como obstáculos na direção do deslocamento. Um aspecto positivo está relacionado às guias de contenção dos canteiros laterais às circulações que ajudam ao deficiente visual, com o uso da bengala, identificar as laterais dos caminhos.

Tabela 4-Percentuais de acessibilidade do Parque João Goulart considerando os componentes da acessibilidade e os públicos estudados

\begin{tabular}{|c|c|c|c|c|}
\hline Componentes acessibilidade & Pessoas com deficiência física & Pessoas com deficiência visual & Idosos & Média final \\
\hline Deslocamento & $59 \%$ & $65 \%$ & $63 \%$ & $62 \%$ \\
\hline Orientação & $80 \%$ & $27 \%$ & $80 \%$ & $62 \%$ \\
\hline Uso & $40 \%$ & $45 \%$ & $43 \%$ & $43 \%$ \\
\hline Comunicação & $71 \%$ & $16 \%$ & $73 \%$ & $53 \%$ \\
\hline
\end{tabular}

Fonte: as autoras.

Em relação a orientação (sinalização tátil direcional e alerta, contraste de cores, elementos referenciais, sinalização sonora em travessias de pedestres e iluminação), os idosos e as pessoas com deficiência física contam com melhores condições em relação as pessoas com deficiência visual, pois, em grande parte do parque, não há sinalização tátil direcional e alerta nos caminhos, semáforos e sinalização sonora em travessias de pedestres. Para deficientes visuais, a falta de um sistema de orientação eficiente compromete significativamente sua autonomia e, mesmo, seu bem estar no ambiente. 
Quanto ao uso (mobiliário adaptado, embarque e desembarque (automóveis e transporte coletivo) e espécies vegetais que não ofereçam riscos ao público alvo), os percentuais são similares para os três tipos de usuários. O parque não possui mobiliário adaptado às necessidades específicas dos usuários, como vasos e lavatórios nos sanitários, lixeiras, bancos e bebedouros, e espaços esportivos adaptados para o público e o próprio playground, como já comentado, cujo piso inviabiliza o uso de pessoas com bengala ou em cadeira de rodas, que eventualmente estejam acompanhando crianças nesses ambientes.

O componente comunicação (sinalizações adequadas, informação de usos, funções e direção, informações em braile e sonoras) prejudica especialmente as pessoas com deficiência visual, já que não se identificou elementos em braile ou sonoros de comunicação.

Os problemas identificados no Parque João Goulart repetem-se em diferentes locais do Brasil e do mundo. O predomínio de sinalizações visuais, sem padrões de exposição foram identificados no estudo realizado por Araújo, Cândido e Leite (2009), ao analisar a acessibilidade de espaços públicos de lazer. Além disso, rampas e escadas sem especificações conforme as normativas e desníveis entre vias de tráfego e as rampas de acesso aos passeios também foram elementos levantados pelos autores citados. Outros itens como os desníveis de piso, que geram acúmulo de água e prejudicam a regularidade e estabilidade, bem como, mobiliário urbano disposto nos passeios, sem sinalizações táteis que possam auxiliar na sua identificação, especialmente tratando-se de pessoas com deficiência visual, foram identificados por Bittencourt (2002), no Brasil, e por Rimmer (2005), Baris e Uslu (2009) e Güngör (2016), em estudos internacionais. No estudo de Silva et al. (2012), que investigou o nível de acessibilidade em um parque na cidade de Campo Grande, Mato Grosso do Sul, todos os itens (passeios, portões de acessos, estacionamento, circulação horizontal, bebedouro, mobiliário, quadra esportiva, parque infantil e coreto), com exceção dos bancos, encontram-se em situação de inacessibilidade, quando comparadas as exigências da NBR 9050. Cassapian e Rechia (2014), ao analisar parques da cidade de Curitiba, também encontraram barreiras como dificuldade de utilização do transporte público para acesso aos espaços livres de lazer, falta de rebaixamento das calçadas, pavimentos como grama e demais revestimentos instáveis, desníveis entre calçadas, escadas, e falta de playgrounds e equipamentos para atividades físicas voltados às pessoas com deficiência. Manta e Palma (2011) analisaram a percepção de PCD, em cadeiras de rodas, sobre a prática esportiva em um parque público. Os entrevistados apontaram barreiras como má conservação de calçadas, desníveis no terreno, canaletas de escoamento de águas pluviais, acúmulo de resíduos, como terra, gravetos e folhas carreados pela chuva, rugosidade do pavimento que impediam o deslocamento ou comprometiam a estabilidade e a conservação da cadeira de rodas. Adiciona-se, também, a falta de equipamentos adequados às possibilidades físicas específicas de PCD e idosos, que torna esses espaços menos atrativos. Pereira (2008) realizou uma análise dos critérios que levaram a sustentabilidade de praças, entre eles a acessibilidade. $O$ estudo aplicado em diferentes praças de Lisboa, Portugal, identificou a má qualidade das travessias de pedestres, a situação precária da pavimentação em alguns pontos, o conflito existente entre os veículos e os pedestres, dado pela alta velocidade dos modais motorizados e pelas poucas opções de travessia. Também foi salientado as barreiras físicas dispostas ao longo dos passeios. Estes problemas, identificados em áreas pública de lazer, repetem-se em ruas que são os canais de acesso dos pedestres aos parques, como apontam estudos de Magagnin, Fontes e Salcedo (2014), Medeiros, Matias e Costa (2016), Magagnin e Menezes (2016) e Yoshida, Alonge e Magagnin (2016), demonstrando que as cidades ainda não estão totalmente resolvidas na orientação da 
inclusão social, da autonomia de seus usuários e em sua comunicabilidade e sociabilidade.

Brandão (2011) fez uma análise da NBR 9050, em sua versão de 2004, e que ainda é válida para sua versão de z015 e emenda de 2020, no que tange a aspectos relacionados aos deficientes visuais. A autora apontou fatores como a recomendação de soluções pontuais dissociadas que dificultam sua aplicação em escalas que vão do mobiliário ao desenho e planejamento urbanos e a compreensão da finalidade das soluções no contexto das habilidades e dificuldades enfrentadas pelo deficiente visual. Adiciona-se à análise de Brandão (2011), recomendações específicas para os três grupos que foram foco desta pesquisa. Sugere-se a aplicação de piso podotátil e mapas táteis de forma a conduzir a todos os elementos do parque, como bancos, playgrounds, bebedouros, lixeiras, etc., bem como nos sanitários, direcionando para o mobiliário específico; ampliar os tipos e tamanhos dos pisos podotáteis de forma a diferenciar escalas da circulação (fluxos, hierarquia, conexões com passeios); ampliar o sistema de informações usando o princípio dos dois sentidos preconizado pela norma, com placas distribuídas em pontos chave de parques e, se possível, com a disponibilização de panfletos com mapas em linguagem comum e em braile; uso de pavimentos com cores contrastantes diferenciando desníveis, bordas, meios-fios e mudança de orientação (importante para pessoas com baixa visão). Também a disponibilização de mobiliário específico, por exemplo; aplicação de piso podotátil nas faixas de travessia de pedestres; mobiliário, como lixeiras, mesas, bancos e bebedouros, com design que permitam o uso confortável tanto do cadeirante, como do idoso, observando a perda da flexibilidade e estatura com a idade. Sugere-se a distribuição deste tipo de mobiliário em todos os ambientes do parque, como junto às quadras poliesportivas, que também devem possibilitar o uso universal, à pista de skate, para garantir acesso universal do PCD e do idoso; disponibilização de vagas exclusivas para ambulância distribuídas em pontos estratégicos; iluminação embutida no piso das circulações; e evitar o uso da cor verde, pois esta pode se confundir com a própria vegetação. Além disso, embora não tenha sido objetivo deste estudo, a orientação de que os parques devem ser pensados como integrantes de um sistema maior composto pelas vias circundantes e pelos modais de mobilidade urbana, pois, não basta o parque ser plenamente acessível, também os caminhos que levam a ele devem propiciar pleno acesso.

\section{Conclusões}

O método adotado, neste estudo, baseado em vistoria técnica com quesitos obtidos da norma NBR 9050 e da literatura, permitiu identificar, de forma objetiva, os problemas relacionados à acessibilidade dos grupos estudados. Ficou evidente a necessidade de avaliações serem feitas conforme o grupo alvo, uma vez que certos quesitos são específicos para determinadas deficiências. Dessa forma é possível entender as potencialidades e deficiências do parque e definir ações que sejam realmente efetivas. Apesar das potencialidades e benefícios do método, identificou-se uma fragilidade especialmente em relação a definição dos quesitos de acessibilidade que, por vezes, são específicos a determinado público o que pode direcionar resultados negativos ou positivos para um público em particular, como por exemplo, a aplicação de pisos podotáteis, elemento mais representativo para as pessoas com deficiência visual. Também, a valoração dos quesitos poderia incorporar uma escala de valores, como a proposta pelo ITDP (2016, p.15) permitindo uma melhor percepção do grau de adequação de cada componente de acessibilidade e dos quesitos específicos da acessibilidade. 
Dentre os três grupos pesquisados, de acordo com os resultados obtidos, os idosos são mais atendidos em suas necessidades. Isso porque, apesar do avanço da idade, as pessoas que não possuem limitações físicas conseguem, na velhice, manter relativa autonomia. Já as pessoas que são portadoras de deficiências, muitas vezes, durante toda a sua vida, enfrentam muito mais limitações. Os deficientes visuais são os menos atendidos. É importante, portanto, que haja maior cuidado em projetos de espaços públicos para atendimento deste grupo. Nota-se que, embora a NBR 9050 seja aplicada, no caso do Parque João Goulart, os elementos estão presentes (rampas, pisos podotáteis, travessias para pedestres, etc.), porém, por vezes, são mal distribuídos, mal posicionados e até incoerentes. Em relação à distribuição, esta é fundamental para garantir o direito de pleno acesso e uso a toda estrutura oferecida, o que não foi verificado no espaço estudado.

Quanto aos componentes de acessibilidade, o uso resultou em um percentual similar aos três grupos e, considerando a média, o valor mais baixo, indicando que o projeto deve prever mobiliário em conformidade com as necessidades dos três grupos. Também os deficientes visuais, para os componentes de orientação e comunicação, foram os mais desfavorecidos, corroborando a necessidade de desenvolver e aplicar soluções específicas para este grupo.

Como sugestão a uma futura revisão da NBR 9050, indica-se, principalmente, recomendações gerais conforme as necessidades específicas de cada grupo e segundo os componentes da acessibilidade, de forma a propiciar um melhor entendimento das tomadas de decisão para a qualidade de vida das PCD e dos idosos.

Avaliações permanentes de acessibilidade espacial são importes para o contínuo aperfeiçoamento de normas e legislação específicas voltadas às necessidades de PCD e idosos, e deveriam ser aplicadas pelo poder público de forma periódica para orientar suas ações nesse campo. Salienta-se que a avaliação, baseada em vistoria técnica, não se esgota, deve ser complementada pela opinião e percepção dos usuários, cujos entretenimento, bem-estar e conforto é o objetivo principal dos espaços públicos de lazer.

\section{Nota}

Este artigo é uma versão estendida do artigo "AVALIAÇÃO DA ACESSIBILIDADE ESPACIAL PARA IDOSO EM PARQUE PÚBLICO” (KLEIN; GRIGOLETTI, 2019) apresentado no SIMPÓSIO IAPS 2019: ENVELHECIMENTO POPULACIONAL EM UM MUNDO DE DESIGUALDADES: COMO PROJETAR CIDADES SAUDÁVEIS PARA TODOS Em 2019 em Pelota - RS.

\section{Referências}

ABNT - ASSOCIAÇÃO BRASILEIRA DE NORMAS TÉCNICAS. NBR 5101: lluminação pública - procedimento. Rio de Janeiro, 2012.

ABNT - ASSOCIAÇÃO BRASILEIRA DE NORMAS TÉCNICAS. NBR 9050: Acessibilidade a edificações, mobiliário, espaços e equipamentos urbanos. Rio de Janeiro, 2020.

AGUIAR, F. O. de. Acessibilidade Relativa dos Espaços Urbanos para Pedestres com Restrição de Mobilidade. 2010. 170 p. Tese (Doutorado Engenharia de Transportes) - Universidade de São Paulo, São Carlos, SP, 2010.

ARANHA, M. S. F. Inclusão Social e Municipalização. In: MANZINI, E. J. Educação Especial: temas atuais. Marília: Unesp: Marília-Publicações, 2000. 
KLEIN, P.; GRIGOletTI, G. de C.

Acessibilidade espacial de deficientes físicos, visuais e idosos em parque público

ARAÚJO, C. D. de; CÂNDIDO, D. R. C.; LEITE, M. F. Espaços Públicos de Lazer: Um Olhar Sobre a Acessibilidade para Portadores de Necessidades Especiais. Licere, Belo Horizonte, v.12, n.4, dez. 2009. DOI:

https://doi.org/10.35699/1981-3171.2009.835

BARIS, E. M.; USLU, A. Accessibility for the disabled people to the built environment in Ankara, Turkey. African Journal of Agricultural Research, v.4, n.9, p.801-814, Sept. 2009.

BITTENCOURT, M. C. Estudos de percursos acessíveis aos portadores de necessidades especiais em espaços abertos na cidade de Maringá. 2002. 246 p. Dissertação (Mestrado em Engenharia de Produção) - Universidade Federal de Santa Catarina, Florianópolis, 2002.

BRANDÃO, Milena de Mesquita. Acessibilidade espacial para pessoas com deficiência visual: discussão e contribuições para a NBR 9050/2004. 2011. 198 p. Dissertação (Mestrado em Arquitetura e Urbanismo) Universidade Federal de Santa Catarina, Florianópolis, 2011.

BRASIL. Constituição da República Federativa do Brasil: promulgada em 5 de outubro de 1988. Câmara dos Deputados.

BRASIL. Presidência da República. Lei n 13.146, de 6 de julho de 2015. Institui a Lei Brasileira de Inclusão da Pessoa com Deficiência (Estatuto da Pessoa com Deficiência). Brasília, 2015.

BRASIL. Presidência da República. Lei n. 10.741, de $1^{\circ}$ de outubro de 2003. Dispõe sobre o Estatuto do Idoso e dá outras providências. Brasília, 2003.

BUFFEL, T.; PHILLIPSON, C.; SCHARF, T. Ageing in urban environments: developing 'age-friendly' cities. Critical Social Policy, v. 32, n. 4, p.597-617, 2012. DOI: https://doi.org/10.1177/0261018311430457

BUSHATSKY, A.; ALVES, L. C.; DUARTE, Y. A. O.; LEBRÃO, M. L. Fatores associados à alterações de equilíbrio em idosos resientes no município de São Paulo em 2006: evidências do Estudo Saúde Bem-Estar e Envelhecimento (SABE). Rev. Bras. Epidemiol., v. 21, suppl.2, e180016. Epub 04-Fev-2019. ISSN 1980-5497. DOI:

https://doi.org/10.1590/1980-549720180016.supl.2

CASSAPIAN, M. R.; RECHIA, S. Lazer para todos? Análise de acessibilidade de alguns parques de Curitiba, PR. Cadernos Brasileiros de Terapia Ocupacional, São Carlos, v. 22, n. 1, 2014, p. 25-38. DOI:

https://doi.org/10.4322/cto.2014.004

DISCHINGER, M.; BINS ELY, v.H.M.; PIARDI, S.M.D. Promovendo acessibilidade espacial nos edifícios públicos: programa de acessibilidade às pessoas com deficiência ou mobilidade reduzida nas edificações de uso público. Florianópolis: MPSC, 2012.

DORNELES, V. G. Acessibilidade para idosos em áreas livres públicas de lazer. 2006. 213 p. Dissertação (Mestrado em Arquitetura e Urbanismo) - Universidade Federal de Santa Catarina, Florianópolis, 2006.

DORNELES, V.G.; BINS ELY, v. H. M. Acessibilidade espacial em espaços abertos. In: VIEIRA, M. S. (org.). O futuro da cidade: Florianópolis. Palhoça: Ed. Unisul, 2013, p.83-108.

FANTINI, F. Acessibilidade espacial para idosos em zonas turísticas balneares costeiras: estudo de caso em Balneário Camburiu/SC. 2014. 388 p. Dissertação (Mestrado em Arquitetura e Urbanismo) - Universidade Federal de Santa Catarina, Florianópolis, 2014.

FROYEN, H. Designing in the dark: an experimental design workshop. In: Devlieger, P.; Renders, F.; Froyen, H.; Wildiers, K. (Ed.). Blindness and the multi-sensorial city. Antwerp: Garant, 2006. p. 329-338 apud BRANDÃO, Milena de Mesquita. Acessibilidade espacial para pessoas com deficiência visual: discussão e contribuições para a NBR 9050/2004. 2011. 198 p. Dissertação (Mestrado em Arquitetura e Urbanismo) - Universidade Federal de Santa Catarina, Florianópolis, 2011. 
KLEIN, P.; GRIGOletTI, G. de C.

Acessibilidade espacial de deficientes físicos, visuais e idosos em parque público

GIL, M. Deficiência visual. Brasília: MEC. Secretaria de Educação a Distância, 2001.

GÜNGÖR, S. A research on accessibility of urban parks by disabled person: the case study of Birlik Park, Konya Turkey. In: EFE, R.; CÜREBAL, I.; GAD, A.; TÓTH, B. (Editors). Environmental Sustainability and Landscape Management. Sofia, Turkey: St Kliment Ohridski University Press, 2016.

IBGE - INSTITUTO BRASILEIRO DE GEOGRAFIA E ESTATÍSTICA. Censo Demográfico 2010: características gerais da população, religião e pessoas com deficiência. Rio de Janeiro, 2020.

IBGE - INSTITUTO BRASILEIRO DE GEOGRAFIA E ESTATÍSTICA. Síntese de Indicadores Sociais: uma análise das condições de vida da população brasileira. 2016.

ITDP - INSTITUTO DE POLÍTICAS DE TRANSPORTE \& DESENVOLVIMENTO. Índice de caminhabilidade: ferramenta. Rio de Janeiro: ITDP, 2016.

KLEIN, Pâmela; GRIGOLETTI, Giane de Campos. Avaliação da acessibilidade espacial para idosos em parque público. In: SIMPÓSIO IAPS 2019: ENVELHECIMENTO POPULACIONAL EM UM MUNDO DE DESIGUALDADES: COMO PROJETAR CIDADES SAUDÁVEIS PARA TODOS, 2019, Pelotas. Anais [...]. Pelotas: IAPS, 2019, p. 414-421. Disponível em: https://iaps-association.org/wp-content/uploads/2020/11/IAPS-2019-Symposium-Book-of-Abstracts-1.pdf. Acesso em: 9 jul. 2021.

MAGAGNIN, R. C.; FONTES, M. S. G. de C.; SALCEDO, R. F. B. Spatial quality evaluation of pedestrian streets. Journal of Civil Engineering and Architecture, v. 8, n.12, p.1567-1574, 2014.

MAGAGNIN, R. C.; MENEZES, P. A. Acessibilidade espacial no Centro Histórico de Santos (Brasil). In: Congreso EuroAmericano REHABEND 2016, Burgos. Anais [...]. Burgos, Espanha: Universidad de Cantabria, Universidad de Burgos, 2016, p.1-9.

MAGAGNIN, R. C.; MOLLES, B. R. Acessibilidade espacial no Centro Histórico de Poços de Caldas (Brazil). In: Congreso Euro-Americano REHABEND 2016, Burgos. Anais [...]. Burgos, Espanha: Universidad de Cantabria, Universidad de Burgos, 2016, p.1-8.

MAGNOLI, M. M. Espaço Livre - Objeto do Trabalho. Paisagem e Ambiente: ensaios, São Paulo, n. 21, p. 175 - 198, 2006. DOI: https://doi.org/10.11606/issn.2359-5361.voi21p175-197

MANTA, S. W.; PALMA, L. E. O parque público como espaço para a prática de atividades esportivas: a percepção das pessoas com deficiência física. 2011. 19p. Monografia (Especialização em Atividade Física, Desenvolvimento Motor e Saúde) - Universidade Federal de Santa Maria, Santa Maria, 2011.

MEDEIROS, H. L. v.; MATIAS, E. B. S. S. E.; COSTA, A. D. L. Resgatando a habitabilidade local: inserção de rota acessível no Centro Histórico de João Pessoa - PB. In: ENCONTRO NACIONAL DE ERGONOMIA DO AMBIENTE CONSTRUÍDO. 6; SEMINÁRIO BRASILEIRO DE ACESSIBILIDADE INTEGRAL, 7., 2016, Recife. Anais [...]. São Paulo: BLUCHER, 2016. DOI: https://doi.org/10.5151/despro-eneac2016-ACE03-4

MESHUR, H. F. A. Accessibility for people with disabilities in urban spaces: a case study of Ankara, Turkey. International Journal of Architectural Research, v.7, Issue 2, p.43-60, July 2013. DOI: http://doi.org/10.26687/ARCHNET-IJAR.V7l2.154

MONTENEGRO, n. G.S.D.; SANTIAGO, Z., M.P.; SOUSA, v. C. DE. Guia de Acessibilidade: espaço público e edificações. Fortaleza: SEINFRA, 2009.

OMS - ORGANIZAÇÃO MUNDIAL DA SAÚDE. Envelhecimento ativo: uma política de saúde. Brasília: Organização Pan-Americana da Saúde, 2005.

OMS - ORGANIZAÇÃO MUNDIAL DA SAÚDE. Relatório mundial sobre a deficiência. São Paulo: Secretaria dos Direitos da Pessoa com Deficiência, 2012. 
KLEIN, P.; GRIGOletTI, G. de C.

Acessibilidade espacial de deficientes físicos, visuais e idosos em parque público

PEREIRA, M. M. D. C. E. Praças públicas sustentáveis: caso de renovação de praças. 2008. Dissertação (Mestrado em Arquitetura) - Universidade Técnica de Lisboa, Lisboa, 2008.

RIMMER, J. H. The conspicuous absence of people with disabilities in public fitness and recreation facilities: lack of interest or lack of access? American Journal of Health Promotion, v. 19, n. 5, May/June 2005, p.327-329. DOI: https://doi.org/10.4278/0890-1171-19.5.327

SANTA ROSA. Prefeitura Municipal. A cidade. Turismo. Sítio eletrônico da PMSR. Santa Rosa: 2004. Disponível em: http://turismo.santarosa.rs.gov.br/?cat=7. Acesso em: 25 out. 2018.

SILVA, J.v.P.; TOSTA, Q. P.; OTTO, H.R.; LINS, A.C.S.; SAMPAIO, T.M.v. Acessibilidade às pessoas com deficiência física e visual no Parque Esportivo Itanhangá. Motricidade, v.8, n. S2, p. 249-258, 2012.

SIU, K. W. M. Accessible park environments and facilities for the visually impaired. Facilities, v. 31, n.13/14, 2013, p. 590-609. DOI: https://doi.org/10.1108/f-10-2011-0079

SOUZA, A. C. de. (Coord.). Brasil 2050: desafios de uma população que envelhece. Brasília: Edições Câmara, 2017.

TAGLIARI, C.; TRÊS, F.; OLIVEIRA, S. G. de. Análise da acessibilidade dos portadores de deficiência física nas escolas da rede pública de Passo Fundo e o papel do fisioterapeuta no ambiente escolar. Revista Neurociências, v. 14, n.1, 2006, p.10-14. DOI: https://doi.org/10.34024/rnc.2006.v14.8781

TERROSO, M.; ROSA, N.; MARQUES, A. T.; SIMOES, R. Physical consequences of falls in the elderly: a literature review from 1995 to 2010. Eur. Rv. Aging Phys. Act. v.11, p.51-59, 2014. DOI: https://doi.org/10.1007/s11556-013-0134-8

VASCONCELLOS, B. C. de. A construção de um método para avaliação do ambiente construído. 2011. 221 f. Tese (Doutorado em Engenharia Civil) - Universidade Federal Fluminense, Niterói, 2011.

WHO - WORLD HEALTH ORGANIZATION. Ageing and health. 2021. Sítio eletrônico da WHO. Disponível em: https://www.who.int/news-room/fact-sheets/detail/ageing-and-health. Acesso em: 22 abr. 2021.

WHO - WORLD HEALTH ORGANIZATION. International Statistical Classification of Diseases and Related Health Problems (ICD-10). 2016a. Sítio eletrônico da WHO. Disponível em: https://icd.who.int/browse10/2016/en\#/H53-H54. Acesso em 04 jun. 2020.

WHO - WORLD HEALTH ORGANIZATION. Urban green spaces and health: a review of evidence. Copenhagen, Denmark: WHO Regional Office for Europe, 2016b. Sítio eletrônico da WHO. Disponível em: http://www.euro.who.int/en/health-topics/environment-and-health/urban-health/publications/2016/urban-greenspaces-and-health-a-review-of-evidence-2016. Acesso em: 11 mai. 2020.

YOSHIDA, D. M.; ALONGE, F. A.; MAGAGNIN, R. C.. Qualidade da acessibilidade espacial do pedestre em um eixo comercial. In: Congresso Luso Brasileiro para o Planejamento Urbano, Regional, Integrado e Sustentável, 7., 2016, Maceió. Anais [...]. Maceió: Viva Editora, 2016, p.1-12.

\section{Pâmela Klein}

Arquiteta e Urbanista. Mestre em Engenharia Civil. Projetista na Liberali Arquitetura e Design. Endereço postal: Rua Guarani, 950, Santa Rosa, RS, Brasil, CEP 98787-344

\section{Giane de Campos Grigoletti}

Arquiteta e Urbanista. Doutora em Engenharia Civil. Professora junto ao Departamento de Arquitetura e Urbanismo da UFSM. Endereço postal: Avenida Roraima, 1.000, Prédio 7, Santa Maria, UF, País, CEP 97105-900 